\title{
Reflexões sobre especificidades didático-pedagógicas dos itens de leitura da avaliação da alfabetização no Brasil
}

\author{
Gladys Rocha
}

Raquel Márcia Fontes-Martins

Vanessa Regina Eleutério Miranda

\section{Resumo}

Duas avaliações externas em alfabetização foram analisadas no contexto da sua implementação e, principalmente, refletindo sobre seus percursos e especificidades didático-pedagógicas: o Programa de Avaliação da Alfabetização do Estado de Minas Gerais (Proalfa) e a Provinha Brasil. Realizou-se uma pesquisa bibliográfica, bem como um levantamento e uma análise de dados dessas avaliações, que permitiram considerar diferentes estratégias na elaboração, aplicação e análise dos itens destinados a avaliar a alfabetização. Há dois tipos de itens: os de modelo único, totalmente lidos pelos alunos, e os de modelo híbrido, parcial ou totalmente lidos pelo aplicador. Os itens de modelo híbrido contribuem para captar informação de estudantes leitores e também de não leitores, o que reflete na identificação de diferentes perfis de aprendizado na alfabetização. Concluiu-se que os modos de construção dos itens fundamentam-se em uma concepção de alfabetização e letramento, conceito que influencia tanto na sua elaboração quanto na seleção para os testes.

Palavras-chave: avaliação da aprendizagem; avaliação da alfabetização; avaliação externa. 


\section{Abstract \\ Reflections on didactic-pedagogical particularities of the reading items of the literacy assessment in Brazil}

In this paper, there is an analysis of two evaluations of literacy in Brazil, approaching the context of its implementation and, mainly, reflecting on their didacticpedagogical paths and specificities, which are: the Programa de Avaliação da Alfabetização do Estado de Minas Gerais (Proalfa) and Provinha Brasil. It was performed a bibliographic research as well as a survey and data analysis on these evaluations, which allowed to verify the importance of considering different strategies in the elaboration, application and analysis of the items aimed to evaluate the literacy. There are two types of items: single model items, which are fully read by students, and hybrid model items, which are partially or fully read by the applicator. Hybrid model items contribute to capture information from student readers, but also from non-reader students, which reflects in the identification of different profiles of literacy learning. It was verified that the ways employed to develop items are underpinned in a notion of literacy and literacy teaching, a concept that influences not only the making but also the selection of items for the evaluation.

Keywords: external evaluation; literacy assessment; literacy program.

\section{Resumen \\ Reflexiones sobre especificidades didáctico-pedagógicas de los ítems de lectura de la evaluación de la alfabetización en Brasil}

Se analizaron dos evaluaciones externas de alfabetización en el contexto de su implementación y, principalmente, reflexionando sobre sus trayectorias y especificidades didáctico-pedagógicas: el Programa de Evaluación de la Alfabetización del Estado de Minas Gerais (Programa de Avaliação da Alfabetização do Estado de Minas Gerais Proalfa) y la Pruebita Brasil (Provinha Brasil). Se realizó una investigación bibliográfica, así como un relevamiento y un análisis de datos de estas evaluaciones, que permitieron considerar diferentes estrategias en la elaboración, aplicación y análisis de los ítems destinados a evaluar la alfabetización. Hay dos tipos de ítems: los de modelo único, totalmente leídos por los alumnos, y los de modelo híbrido, leídos total o parcialmente por el aplicador. Los ítems del modelo híbrido contribuyen a captar información de los estudiantes lectores y también de los no lectores, lo que se refleja en la identificación de diferentes perfiles de aprendizaje en alfabetización. Se concluyó que los modos de construcción de los ítems se basan en una concepción de alfabetización, concepto que influye tanto en su elaboración como en la selección para los test.

Palabras clave: evaluación del aprendizaje; evaluación externa; programa de alfabetización. 


\section{Introdução}

No Brasil, a avaliação da educação básica externa à escola vem amadurecendo ao longo das últimas décadas, com experiências consolidadas, a exemplo do Sistema de Avaliação da Educação Básica (Saeb), em âmbito federal. Foram muitos os desafios para implementá-lo e consolidá-lo. Na alfabetização, os desafios ganham novos contornos, sobretudo em função de um público - crianças dos anos iniciais do ensino fundamental (EF) - com características que demandam procedimentos específicos na elaboração, aplicação e análise da avaliação (Rocha; Fontes-Martins, 2014)

Este texto discute a implementação da avaliação externa à escola no Brasil, procurando avaliar modos de organização pedagógica, no que tange a possibilidades de apreensão de habilidades de alfabetização. Para tanto, tem-se como referência dois programas que se destacam como as primeiras avaliações externas à escola produzidas em larga escala (uma estadual, outra nacional), implementadas, respectivamente, em 2005 e 2008: o Programa de Avaliação da Alfabetização do Estado de Minas Gerais (Proalfa) e a Provinha Brasil. A fim de situar a construção de formas de estruturação pedagógica da avaliação da alfabetização, detemo-nos brevemente na história recente da implementação dessa avaliação no País, focalizando os dois programas. Assim, o objetivo principal deste estudo é promover uma reflexão sobre seus percursos e especificidades didático-pedagógicas.

A opção pelo Proalfa e pela Provinha Brasil se justifica, por um lado, pelo caráter inédito dessas avaliações e, por outro, por se tratar de avaliações que nos permitiram fazer uma análise aprofundada de sua organização didático-pedagógica ao longo de várias edições. ${ }^{1}$

Na próxima seção, são apresentadas notas sobre a implementação de avaliações externas em alfabetização. Nas duas seções seguintes, são abordados percursos e especificidades da avaliação da alfabetização. Em seguida, são realizadas as considerações finais.

\section{Notas sobre a implementação de avaliações externas em alfabetização}

Embora os estudos e testes-piloto do Saeb, de certo modo, já sinalizassem uma tendência de avaliar o ensino mais precocemente, foi sobretudo a partir do início de 2000 - quando as inovações metodológicas implementadas em 1995 permitiram a divulgação de resultados a partir de uma série histórica com a possibilidade de comparar resultados estudantis entre anos escolares ao longo do tempo -, que se começou a discutir possíveis motivadores dos desempenhos.

\footnotetext{
${ }^{1}$ Gladys Rocha e Raquel Fontes-Martins participaram como especialistas em avaliação da alfabetização no Proalfa desde sua implementação até a edição de 2012. Participaram, também, na implementação da primeira edição da Provinha Brasil (entrada e saída), atuando em todo o processo didático-pedagógico dessas avaliações.
} 
Os dados do Saeb, particularmente os de 2001 e de 2003, indiciavam possíveis relações entre o insucesso escolar das crianças na $4^{\mathrm{a}}$ série e em alfabetização. Segundo os Resultados do Saeb 2003, 55\% dos estudantes estavam nos níveis de leitura "muito crítico" - "não desenvolveram habilidades de leitura mínimas condizentes com quatro anos de escolarização. Não foram alfabetizados adequadamente. Não conseguem responder os itens da prova" - ou "crítico" "leitores ainda no nível primário, decodificam apenas a superfície de narrativas simples e curtas, localizando informações explícitas, dentre outras habilidades" (Brasil. Inep, 2004, p. 34). Em síntese, em ambos os níveis, os alunos não demonstravam compreender textos simples e curtos.

Sem desconsiderar a complexidade subjacente à noção do que se entende por compreender um texto, bem como a diversidade de fatores inerentes à alfabetização e à própria avaliação, a divulgação desses resultados teve grande impacto no cenário educacional. Eles indiciavam que as dificuldades em leitura poderiam estar relacionadas à não alfabetização das crianças no início do ensino fundamental. Ao lado disso, a meta estabelecida pelo governo federal, em 2001, no Plano Nacional de Desenvolvimento da Educação, de que toda criança aprendesse a ler até os oito anos de idade parecia ter se constituído como importante indutor na instituição de projetos de avaliação da alfabetização externos à escola.

Esse cenário potencializou a demanda de avaliar a alfabetização. O objetivo anunciado era avaliar mais precocemente para intervir também mais precocemente, visando à adoção de estratégias de gestão do sistema ou do ensino, voltadas à maior equidade nos aprendizados.

Para tal, fazia-se necessária a construção de um novo modelo de avaliação externa à escola, passível de utilização em larga escala, com alunos de $2^{\circ}$ ou $3^{\circ}$ ano do EF. Mas, como avaliar grandes contingentes de alunos, procurando considerar seus diferentes níveis de aprendizado (ou padrões de desempenho), sem a dicotomia "aluno leitor versus aluno não leitor", já constatada a partir dos resultados obtidos ao final da $4^{\mathrm{a}}$ série $/ 5^{\mathrm{o}}$ ano? Como aprofundar nossos conhecimentos sobre os saberes demonstrados pelos alunos em processo de alfabetização? Como produzir um design de avaliação que permitisse identificar perfis de aprendizado na alfabetização, buscando apreender diferentes níveis do que é saber ou não saber ler?

Refletir sobre essas questões nos parece fundamental para se implementar uma avaliação da alfabetização. A próxima seção busca situar percursos didáticopedagógicos empreendidos na construção das duas avaliações em análise (Proalfa e Provinha Brasil), cujos modelos de construção de itens orientam a maior parte das avaliações da alfabetização em curso no País.

\section{Reflexões sobre os percursos de implementação do Proalfa e da Provinha Brasil no contexto da avaliação da alfabetização}

Este estudo se detém nos percursos das avaliações do Proalfa (2005) e da Provinha Brasil (2008) por terem sido, respectivamente, os primeiros programas de 
avaliação da alfabetização externos à escola em âmbito estadual e nacional. No entanto, cabe ressaltar, como afirma Horta Neto (2007), que houve e ainda há outras importantes experiências em avaliação da alfabetização, como os estudos desenvolvidos para a constituição do próprio Saeb, então denominado Sistema de Avaliação do Ensino Público de $1^{\circ}$ grau (Saep), que, em seus testes-piloto realizados nos estados do Paraná e do Rio Grande do Norte, englobaram os primeiros anos do ensino fundamental.

Embora tenham havido experiências anteriores de avaliação externa à escola nos primeiros anos do ensino fundamental, o Proalfa, desenvolvido pelo Centro de Alfabetização, Leitura e Escrita (Ceale), foi a primeira avaliação da alfabetização em larga escala a propor, desde sua primeira edição, em 2005, um design que visava, a partir da construção de itens de leitura, ${ }^{2}$ a apreensão de diferentes níveis de alfabetização.

Em sua primeira edição, o objetivo anunciado do Proalfa era avaliar impactos da ampliação do EF de nove anos, iniciada em Minas Gerais, em 2004. Foram avaliados, considerando-se a unidade "turma", cerca de 11 mil alfabetizandos matriculados em escolas das redes estadual e municipal. Naquele momento, embora os dados não permitissem analisar aprendizados agregados pelas crianças quando de seu ingresso no ensino fundamental, a comparação de resultados obtidos por crianças de seis e sete anos de idade indicava que a ampliação do tempo de permanência do estudante no EF corroborava para seu aprendizado (Cafiero; Rocha; Soares, 2007).

A aplicação amostral de 2005 teve um importante papel na delimitação de tipos e formatos de itens adequados à avaliação da alfabetização externa à escola. A análise dos itens e das respostas produzidas pelos alunos possibilitou a constituição de uma meta-avaliação, que criou condições para que, em 2006, a proposta de avaliação da alfabetização tivesse seus objetivos redefinidos e ampliados, passando a ser censitária e anualmente aplicada aos alunos do $3^{\circ}$ ano do EF. Ao lado dessa primeira meta-avaliação dos itens, foram feitos ajustes nas estratégias de aplicação, que requeriam procedimentos bastante distintos daqueles adotados para os alunos de $5^{\circ}$ e $9^{\circ}$ ano do $\mathrm{EF}^{3}$

Em 2008, tendo como ponto de partida a experiência desenvolvida no design dos testes do Proalfa, foi criada a Provinha Brasil - primeira avaliação da alfabetização a ser proposta pelo Instituto Nacional de Estudos e Pesquisas Educacionais Anísio Teixeira (Inep). Com o objetivo precípuo de colaborar com os municípios e com as escolas na identificação de perfis de alfabetização no $2^{\circ}$ ano de escolarização do EF, a Provinha Brasil propõe uma dinâmica bastante distinta das demais avaliações que

\footnotetext{
${ }^{2}$ Embora também tenham sido utilizados, desde a primeira edição, itens de escrita, os dados com os quais foi construída a escala do Proalfa tiveram origem, fundamentalmente, nos itens de leitura. Em uma primeira etapa, havia dificuldades na utilização de medidas estatísticas para fazer o processamento dos dados de escrita. Havia, já naquele momento, as dificuldades que ainda hoje se encontram quanto ao grau de confiabilidade da correção dos itens de escrita, uma vez que, mesmo havendo critérios préestabelecidos para a correção e o acompanhamento da atividade, o grau de subjetividade ainda era alto.

${ }^{3}$ A implementação do Proalfa, mesmo em sua edição amostral, deveu-se também ao fato de a Superintendência de Avaliação Educacional (SAE) do estado ter larga experiência na gestão de um sistema já consolidado, o Sistema Mineiro de Avaliação da Educação Pública (Simave).
} 
compõem o Saeb. Embora apresente um conjunto de orientações acerca da aplicação, correção, análise e discussão de resultados, essa avaliação foi planejada para ocorrer de forma descentralizada, sob a coordenação das escolas e secretarias, sem que os testes aplicados ou os resultados obtidos fossem centralizados no Inep. A opção por um formato descentralizado se justificava, sobretudo, por dois motivos:

1) a possibilidade de acesso a um diagnóstico padronizado, cujos resultados pudessem ser comparados sem fomentar rankings e/ou políticas de responsabilização em um momento ainda tão precoce da escolarização; e

2) a expectativa de que o acesso aos resultados da avaliação, pouco tempo após sua aplicação, contribuísse para que os professores, as escolas e as redes, ao ampliarem os diagnósticos já produzidos em sala de aula, ampliassem também as condições para que a escola e o sistema pudessem intervir mais precocemente, visando à alfabetização dos alunos.

Havia, ainda, a expectativa audaciosa de que o protagonismo do professor na aplicação, correção e análise de resultados contribuísse para sua formação.

Feita essa breve incursão nos percursos das avaliações em análise, passamos a discutir os principais aspectos ou especificidades do design didático-pedagógico e da produção de itens de leitura das avaliações externas à escola em alfabetização que nortearam o Proalfa, a Provinha Brasil, bem como a maior parte das avaliações externas à escola hoje em curso no País, como a própria Avaliação Nacional de

74 Alfabetização (ANA).

\section{Especificidades da organização didático-pedagógica de avaliações da alfabetização externas à escola}

A fim de explicitar mais claramente a diferença entre os testes de leitura destinados a alunos dos anos finais do EF e os destinados a turmas de alfabetização, passamos a categorizá-los em modelo único e modelo híbrido.

Os testes de modelo único são compostos por itens de múltipla escolha totalmente lidos pelo aluno, em que comando(s), enunciado(s), texto(s) e alternativas devem ser lidos exclusivamente pelo estudante. Via de regra, pressupõem um aluno "leitor", geralmente a partir do $5^{\circ}$ ano do ensino fundamental.

Já os testes de modelo híbrido, desenhados para avaliar a alfabetização, além de apresentarem itens totalmente lidos pelo aluno, contêm itens parcialmente lidos e totalmente lidos pelo aplicador. No caso dos itens parcialmente lidos, cabe ao aplicador fazer a leitura do comando e/ou do enunciado. Normalmente, são questões que demandam habilidades como reconhecimento de letra(s); leitura de palavras; identificação de informações em textos curtos (frases, sobretudo); e interpretação de textos não verbais. O propósito é retirar do aluno a obrigação de ler o enunciado em situações em que o esforço interpretativo dele poderia ser igual ou maior do que o que lhe é requerido para responder ao item. 
Os itens totalmente lidos pelo aplicador focalizam habilidades que não pressupõem o domínio da leitura. Com menor incidência, esses itens se vinculam a habilidades que podem ser demonstradas pelos alunos que ainda não apresentam uma fluência leitora que lhes permita ler o item de forma autônoma. Ou seja, esse tipo de item deve ser usado quando a principal habilidade requerida e seu grau de complexidade não pressuponham a leitura autônoma das alternativas. Em geral, referem-se a habilidades como o reconhecimento da finalidade ou do gênero de um texto, ou à interpretação de texto não verbal. O estudante pode, por exemplo, ser capaz de inferir o sentido de uma tirinha sem ou com pequena quantidade de texto verbal, mas ainda não demonstrar a habilidade de, no tempo destinado à resposta ao item, decodificar e/ou recuperar o sentido de cada alternativa. Normalmente, quando há esse tipo de ocorrência, a avaliação contempla itens referentes à mesma habilidade, com diferentes graus de complexidade e, em algumas situações, gêneros textuais também distintos.

Esse design de teste com itens de modelo híbrido, embora, à primeira vista, possa não apresentar diferenças perceptíveis, decorre da necessidade de construção de estratégias didático-pedagógicas que viabilizem, a partir de uma avaliação externa com itens de múltipla escolha com habilidades de leitura, identificar diferentes perfis de aprendizado em alfabetização. Afinal, não se pode negligenciar o fato de que, para tal, os testes devem conter itens relacionados a habilidades diversas, com níveis de complexidade distintos que contemplem diferentes momentos do continuum de habilidades inerentes à alfabetização.

No que tange à organização dos testes, a adoção do modelo híbrido demanda, ainda, a elaboração de dois cadernos de avaliação: o do aplicador e o do aluno. O Caderno do Aplicador apresenta, para cada questão do teste por completo, os aspectos a serem observados durante o processo de aplicação. Informa, normalmente com a apresentação de um ícone (como megafone ou microfone), o que deve ser lido oralmente pelo aplicador. Já o Caderno do Aluno é composto apenas pelo conjunto de itens a serem respondidos, sem os comandos e/ou enunciados, que devem ser lidos pelo aplicador e para os quais há, no Caderno do Aplicador, indicação de oralização. Vale ressaltar que, quando o enunciado é lido pelo aplicador, não aparece registrado no Caderno do Aluno, a fim de não criar condições diferenciadas na produção da resposta em decorrência das condições de realização do teste. Esperase que as diferenças decorram, fundamentalmente, dos conhecimentos mobilizados pelo estudante.

Assim, analisaremos dois itens: o primeiro é do Proalfa; o segundo, da Provinha Brasil. Eles são, respectivamente, "parcialmente lido" e "totalmente lido" pelo aplicador. A intenção é ilustrar tipos de itens de modelo híbrido, adequados e necessários à avaliação da alfabetização como se discutiu. ${ }^{4}$ Cabe destacar que a finalidade não é apresentar um item exemplar, mas problematizar possíveis aspectos quanto ao que cada item pode informar para essa avaliação.

\footnotetext{
${ }^{4}$ Neste texto, a opção por discutir somente itens de modelo híbrido - parcialmente e totalmente lidos pelo aplicador - se deve ao fato de o item totalmente lido pelo aluno (aqui denominado modelo único), é de amplo conhecimento, muito difundido e utilizado nas avaliações em geral.
} 


\section{INSTRUÇÕES PARA O APLICADOR}

ATENÇÃO:

Ler para o aluno as instruções e as alternativas.

Repetir a leitura, no máximo, uma vez.

\section{MOSTRAR:}

Para o aluno o cartaz com o texto e as alternativas.

DIZER:

(j)) Leia o texto e responda à questão.

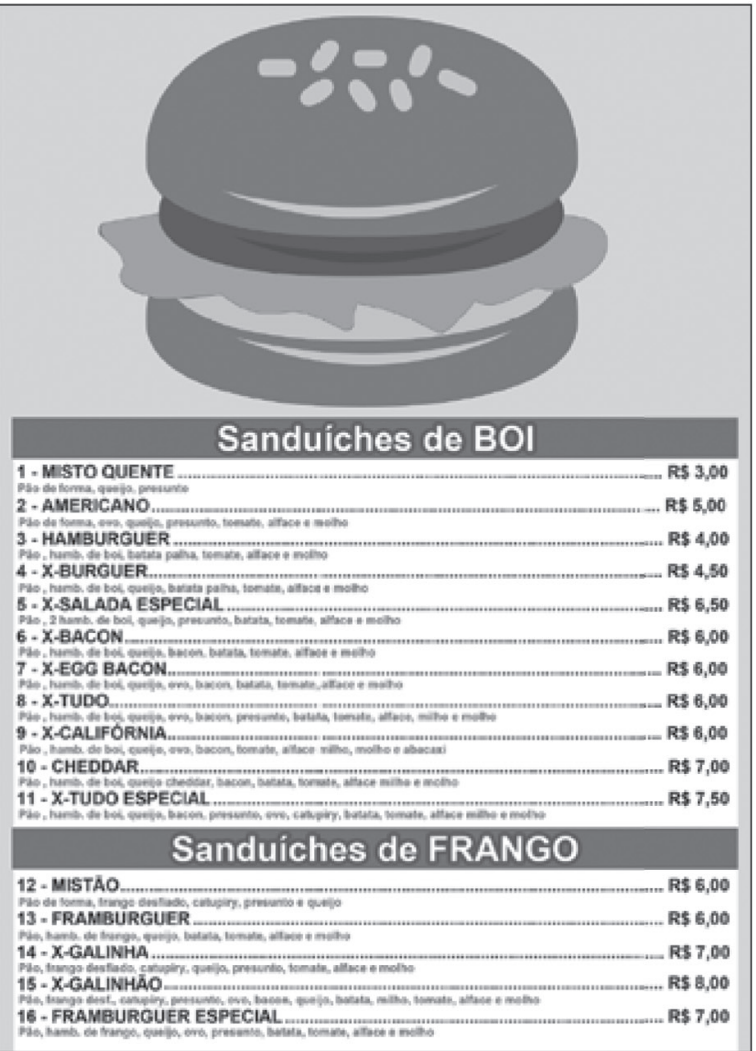

ESSE TEXTO É

UM AVISO.

UM CARDÁPIO

UMA PROPAGANDA.

UMA RECEITA.

Figura 1 - Habilidade: identificar gênero textual - Caderno do Aplicador Proalfa - 2011 
O item da Figura 1 pode ser caracterizado como parcialmente lido, uma vez que, como demonstram as instruções para o aplicador, este deverá ler para o aluno as instruções (o comando) e as alternativas. O texto deverá ser "lido" pelo aluno. Entretanto, o modo como o texto presente no item é estruturado não necessariamente requer a leitura para a identificação do gênero textual ou mesmo de sua finalidade. Além da composição com informação visual típica (imagem de comida, no caso, a do hambúrguer), há uma série de informações paratextuais que dão pistas para o reconhecimento do gênero "cardápio", sem que haja a realização da atividade de leitura propriamente dita.

Nota-se que, sem a mediação do aplicador - se esse fosse um item de modelo único, totalmente lido pelo aluno -, um estudante poderia, mesmo sabendo a resposta, não ter condições de identificá-la, por não dominar ainda a habilidade de decodificar, com certa fluência, o comando e as alternativas, o que poderia comprometer a recuperação das informações. Nesse caso, o nível de informatividade do item poderia ficar comprometido em seu potencial pedagógico.

Assim, em uma revisão desse item, apenas se recomendaria que fossem utilizados megafones à frente do comando e das alternativas, para indicar ao aplicador que ele deve ler as alternativas também para os alunos. Essa estratégia de não exigir a leitura do comando e das alternativas para os estudantes auxilia a obter informações mais fidedignas sobre os conhecimentos que eles realmente têm em relação à habilidade focalizada pelo item que, embora possa apresentar respostas diferenciadas em função dos distintos contextos de letramento social e escolar nos quais os sujeitos estão inseridos, não criaria a dicotomia "aluno leitor versus aluno não leitor".

A Figura 2 apresenta o segundo e último item em análise, proveniente da Provinha Brasil.

Como demonstra a instrução para o aplicador, esse segundo item pode ser caracterizado como totalmente lido (comando e alternativas) pelo aplicador e os ícones de megafone reforçam essa característica. Esse item focaliza a habilidade de identificar a sílaba inicial de uma palavra. Trata-se, portanto, de uma habilidade relacionada à consciência fonológica (Morais, 2019), essencial à alfabetização. Essa habilidade não demanda, necessariamente, um aluno leitor. O aluno pode conseguir identificar unidades sonoras da língua (como a sílaba e o fonema) antes mesmo de ler e escrever. Assim, torna-se fundamental que esse tipo de item seja totalmente lido pelo aplicador, para que não exija um aluno leitor, mas capte informação sobre tal habilidade também em alunos não leitores.

No item, a palavra "jacaré", apresenta o "já" ${ }^{5}$ como sílaba inicial. Por meio da pronúncia das palavras das alternativas pelo aplicador, o aluno deveria ser capaz de reconhecer que, entre elas, a única que começa exatamente com essa sílaba seria "janela". Cabe ressaltar, no entanto, que, a depender da fala do aluno - por exemplo, se for falante do dialeto baiano -, a sílaba inicial passa a ser com vogal nasal e não oral, como a pronúncia "jãnela". Nesse caso, em uma revisão do item, seria interessante trocar essa palavra por outra que não apresentasse variação dialetal na pronúncia da sílaba inicial, como seria o caso de "jabuti" ou de "jatinho".

\footnotetext{
${ }^{5}$ As pronúncias das palavras ou sílabas não estão representadas em transcrição fonética para não comprometer a leitura deste trabalho com uma notação técnica, específica da área de linguística. Optouse por uma representação simplificada, baseada na escrita alfabética, utilizando-se aspas, para indicar que se trata de uma palavra, sílaba falada ou som.
} 


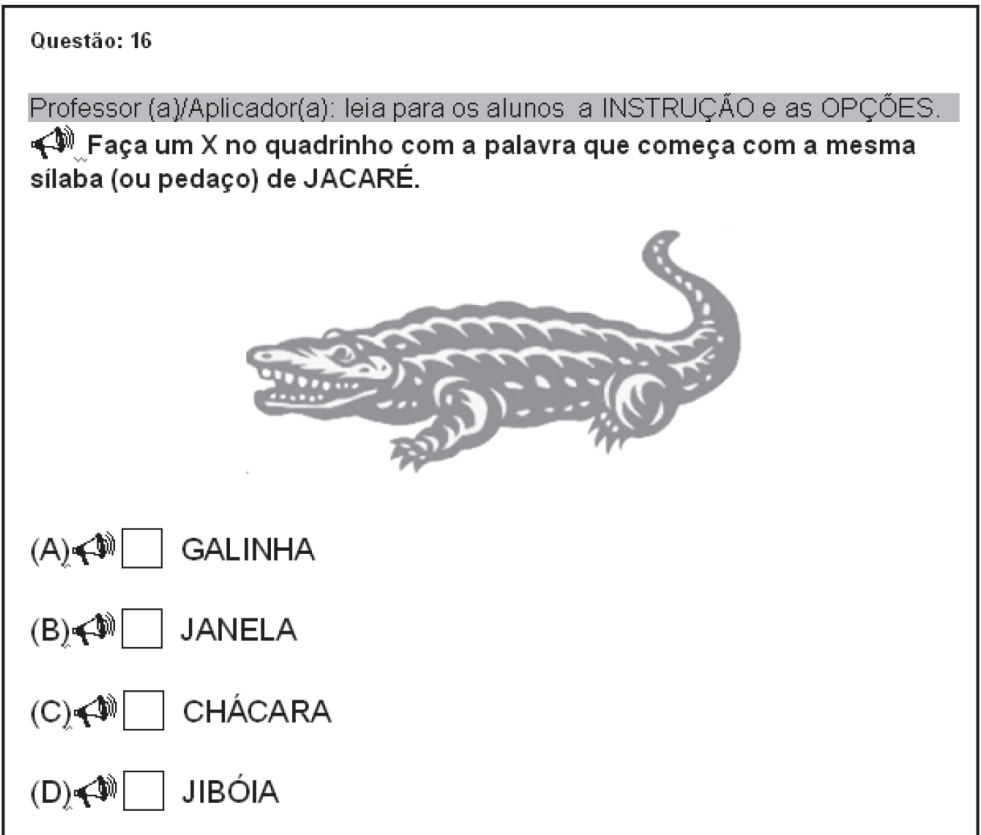

\section{Figura 2 - Habilidade: identificar a sílaba inicial de uma palavra - Caderno do Aplicador}

Fonte: Brasil. Inep (2008, p. 28).

As demais alternativas contêm letras que representam sons semelhantes aos da sílaba inicial de "janela", com destaque para "jiboia", que começa exatamente com o mesmo fonema, mas não com a mesma sílaba. Um aluno que tenha marcado a palavra "jiboia" aproximou-se do reconhecimento da sílaba inicial, por identificar o som inicial igual em "janela" e "jiboia" ("jê"), mas não acertou o item, por não ter reconhecido que o som seguinte ("a") é diferente do som "i" da sílaba inicial de "jiboia".

A palavra "chácara", outra alternativa desse item, apresenta o som inicial "chê", semelhante ao som inicial "jê" de "janela" e vogal seguinte a esse som ("a") idêntica à de "janela". O aluno que marcou "chácara" se aproximou, mas não domina a habilidade, por confundir um som sonoro, "jê" (som inicial de "janela"), com um som surdo, "chê" (som inicial de "chácara").

Por fim, na palavra "galinha", a primeira alternativa, possui a letra inicial ("g") que representa o som "jê" (presente em "janela") em palavras em que a letra " $g$ " venha seguida das vogais "e" ou "i", como em "gente" ou em "girafa". No entanto, diante de "a", como em "galinha", a letra "g" representa o som "guê", portanto, diferente do som "jê". Assim, o aluno que marcou "galinha" parece ter se distanciado mais da habilidade requerida no item, por optar por uma palavra com som inicial ("guê" de "galinha") que se difere do "jê" de "janela".

Toda essa minúcia de análise das sílabas das palavras das alternativas com a da palavra do comando poderia ser perdida caso o item não fosse totalmente lido pelo aplicador. Alunos não leitores que apresentam essa habilidade desenvolvida não teriam a oportunidade de serem captados na avaliação. Assim, 
mais uma vez, se destaca a importância de se considerar as especificidades da avaliação da alfabetização na elaboração, aplicação e análise dos itens que compõem os testes.

Por fim, embora o aprofundamento da temática sobre avaliação da escrita ultrapasse o escopo deste texto, cabe ressaltar que a maioria dos sistemas que avaliam a alfabetização, quer com o modelo híbrido, quer com o modelo único, avalia também a escrita. Há avaliações que contemplam a escrita de palavras ou a produção de um texto com ênfase na narrativa. Há, ainda, avaliações da alfabetização que contemplam itens de escrita com níveis de complexidade diversificados, como composição de uma frase e escrita de frases ditadas e de palavras (com ou sem o apoio de imagens).

É importante estar atento ao fato de que, mesmo diante de uma possível fragilidade no nível de informatividade dos itens de leitura a partir de seus posicionamentos na escala, não se pode tomar os dados de escrita como norteadores para a construção da escala de desempenho dos alunos. Para além de todas as ponderações que devem ser feitas a partir da correção de itens de escrita, há que se considerar o fato de que o aprendizado da leitura e da escrita não podem ser analisados como se fossem simultâneos, ou seja, não se pode tomar os dados de escrita como referência para a construção de uma escala de aprendizado da leitura, como se se tratasse de faces de uma mesma moeda. Embora o ensino seja simultâneo, os dados obtidos a partir das avaliações devem evidenciar os avanços dos alunos em "alfabetização em leitura" e em "alfabetização em escrita" (Rocha; Fontes-Martins, 2014).

\section{Considerações finais}

Do ponto de vista de sua organização pedagógica, a caracterização dos itens de múltipla escolha destinados a avaliações externas da alfabetização, nos modelos único e híbrido, pode permitir a identificação de diferentes perfis de aprendizado em alfabetização. Se, em um teste desse tipo de avaliação, fossem utilizados somente itens de modelo único, ou seja, totalmente lidos pelos alunos, isso não permitiria verificar habilidades de leitura que os estudantes poderiam apresentar, mas que não demandam necessariamente a decodificação, como ocorre no caso das habilidades de identificar um gênero textual ou de identificar a sílaba inicial de palavra, exploradas em exemplos neste artigo.

Acredita-se que a compreensão sobre a existência de diferentes modelos pedagógicos de itens de leitura pode contribuir não apenas para uma tipificação de itens de leitura em avaliações da alfabetização, mas também para uma discussão mais ampla das concepções e do nível de informatividade inerentes a um ou outro tipo. Há que se observar que a opção pelo uso de itens de modelo único ou híbrido (ou sua articulação) está estritamente relacionada ao que se visa, de fato, apreender a partir da avaliação: identificar alunos leitores versus apreender níveis de alfabetização. Tem-se, assim, que a tipificação de itens proposta neste estudo está 
relacionada a aspectos que envolvem diferentes formas de elaboração e aplicação e das leituras múltiplas que podem ser feitas a partir dos seus resultados.

Na esteira dessa discussão, encontram-se relações menos aparentes, como o grau de complexidade de habilidades avaliadas, as diferenças entre matrizes, bem como a potencialidade e qualidade dos itens propostos na aferição de habilidades de leitura. Não se pode perder de vista que, aos modos de construção dos itens de avaliação, está subjacente uma concepção de alfabetização e letramento que precisa ser tratada de forma mais clara, uma vez que esse conceito se traduz nas escolhas feitas tanto na elaboração quanto na seleção dos itens de testes (Soares, 1999).

\section{Referências bibliográficas}

BRASIL. Instituto Nacional de Estudos e Pesquisas Educacionais Anísio Teixeira (Inep). Provinha Brasil: caderno do professor/aplicador - primeiro semestre 2008. Brasília: Inep, 2008. Disponível em: < http://download.inep.gov.br/educacao_ basica/ provinha_brasil/kit/2008/1_semestre/caderno_professor_1-2008.pdf>. Acesso em: set. 2020

BRASIL. Instituto Nacional de Estudos e Pesquisas Educacionais Anísio Teixeira (Inep). Resultados do Saeb 2003: Brasil. Brasília: Inep, 2004. Disponível em: <http://download.inep.gov.br/download/saeb/2004/resultados/BRASIL.pdf> . Acesso em: 18 jul. 2020.

CAFIERO, D.; ROCHA, G.; SOARES, J. F. Avaliação do ciclo inicial de alfabetização em Minas Gerais: o que indicam os primeiros resultados. Língua Escrita, Belo Horizonte, n. 1, p. 84-102, jan./abr. 2007.

HORTA NETO, J. L. Um olhar retrospectivo sobre a avaliação externa no Brasil: das primeiras medições em educação até o Saeb de 2005. Revista Ibero-Americana de Educación, Madri, v. 42, n. 5, p. 1-14, 2007. Número especial.

MORAIS, A. G. Consciência fonológica na educação infantil e no ciclo de alfabetização. Belo Horizonte: Autêntica, 2019.

ROCHA, G.; FONTES-MARTINS, R. M. A apropriação de habilidades de leitura e escrita na alfabetização: estudo exploratório de dados de uma avaliação externa. Ensaio: Avaliação e Políticas Públicas em Educação, Rio de Janeiro, v. 22, n. 85, p. 977-1000, out./dez. 2014.

MINAS GERAIS. Secretaria de Estado de Educação (SEE/MG). Simave/Proalfa 2011: $3^{\circ}$ ano do ensino fundamental [português]. Revista Pedagógica, CAEd, Juiz de Fora, v. 3, jan./dez. 2011. Disponivel em: < http://www.simave.caedufjf.net/wpcontent/uploads/2012/06/PROALFA_VOL3_2011.pdf>. Acesso em: 9 out. 2020.

SOARES, M. Letramento: um tema em três gêneros. Belo Horizonte: Autêntica: Ceale, 1999. 
Gladys Agmar Sá Rocha, doutora em Educação pela Universidade Federal de Minas Gerais (UFMG), possui dois pós-doutorados: um pela Pontifícia Universidade Católica do Rio de Janeiro (PUC-Rio) e o outro pela Université Laval (ULaval - Canadá). É professora associada (aposentada) da Faculdade de Educação da UFMG e colaboradora da linha Didática e Docência, do mestrado profissional dessa universidade. Coordena o Grupo de Pesquisa Didaktikè e, como professora convidada, atua como consultora na formação docente e na área de avaliação externa à escola em vários projetos.

gladysrocha1@gmail.com

Raquel Márcia Fontes-Martins, doutora em Linguística pela Universidade Federal de Minas Gerais (UFMG), é professora associada do curso de licenciatura em Letras da Universidade Federal de Lavras (Ufla). Atua nas áreas de Linguística (Fonética e Fonologia, Aquisição da Linguagem e Sociolinguística), Linguística Aplicada (Alfabetização e Letramento, Ensino de Língua Portuguesa) e Educação (Avaliação Educacional e Formação de Professores).

raquelfontesmartins@gmail.com

Vanessa Regina Eleutério Miranda, doutora em Educação pela Universidade Federal de Minas Gerais (UFMG) e especialista em Educação Musical e Ensino de Artes pela Universidade Cândido Mendes (Ucam), é professora adjunta do Departamento de Métodos e Técnicas de Ensino, na Faculdade de Educação (FaE) da UFMG, e coordenadora institucional do Pibid/UFMG. É membro do Grupo de Pesquisa Didaktikè e atua com as temáticas relacionadas à Didática, ao Currículo, à Formação de Professores e à Diversidade Cultural (Relações Étnico-Raciais e Gênero). vanessa.elm@gmail.com

Recebido em 30 de março de 2020

Aprovado em 15 de julho de 2020 